\title{
DISTRIBUCION Y ESTADO CULTURAL DE LOS GRUPOS MAYANCES DEL MEXICO ACTUAL*
}

\author{
Por Alfonso Villa Rojas. \\ Universidad Nacional Autónoma de México.
}

En estas notas habremos de limitarnos a los grupos Mayances que habitan el sureste de la República, en las entidades de Yucatán, Campeche, Quintana Roo, Tabasco y Chiapas; no incluimos a los Huastecos por razón de corresponder a un área cultural distinta. Los grupos citados comprenden en la actualidad una población que sobrepasa al medio millón de habitantes, distribuidos sobre un territorio que presenta las más diversas condiciones topográficas y climáticas: desde las zonas anfractuosas y frías de los Altos de Chiapas hasta las llanuras calcáreas y siempre cálidas de la Península Yucateca. Como es de suponerse, las formas de vida presentan marcadas diferencias entre una y otra región. En términos generales, los pueblos más conservadores y aislados se encuentran en las rugosidades de las tierras altas, en tanto que, en los pueblos de las llanuras, ya se nota un grado avanzado de aculturación; desde luego, el porcentaje de monolingües, o sea, de indígenas que desconocen el español, alcanza el $50 \%$ de la población de las tierras altas y sólo el $9 \%$ de la que corresponde a las tierras bajas. Este sólo dato permite entrever la distancia cultural que existe entre las dos regiones.

Los grupos a que vamos a referirnos son ocho, y se les designa con los nombres que siguen: Mayas, Tzeltales, Tzotziles, Choles, Tojolabales, Mames, Chontales y Lacandones. Razones de espacio nos obligan a ser extremadamente breves en la descripción de cada uno de ellos; sin embargo, el lector interesado podrá remediar esta deficiencia acudiendo a las citas bibliográficas que habremos de ofrecerle aquí.

* Las notas que aquí se presentan constituyen una breve síntesis del libro en preparación sobre Etnografía de los Grupos Mayances de México, que publicará el Seminario de Cultura Maya. 


\section{Los Mayas de Yucatán.}

En este grupo incluimos a toda la población indígena de la Península, ya que habla la misma lengua y procede del mismo núcleo étnico; se distribuye en forma muy desigual a través de las tres entidades que la integran, que son: Yucatán, Campeche y el Territorio de Quintana Roo, según puede verse en el cuadro que presentamos a continuación:

HABLANTES DE LA LENGUA MAYA

(Censo de 1950)

\begin{tabular}{|c|c|c|c|c|c|}
\hline Entidades & $\begin{array}{l}\text { Población de más } \\
\text { de } 5 \text { años de edad. }\end{array}$ & $\begin{array}{l}\text { Habla Maya } \\
\text { solamente. }\end{array}$ & $\begin{array}{c}\text { Habla Mayya } \\
\text { y Español. }\end{array}$ & $\begin{array}{l}\text { Total hablantes } \\
\text { del Maya. }\end{array}$ & $\%$ \\
\hline Yucatán & 437,493 & 43,523 & 235,857 & 279,380 & 63.8 \\
\hline CAMPECHE & 103,086 & 5,351 & 27,465 & 32,816 & 31.8 \\
\hline Quintana Roo & 21,937 & 1,335 & 8,264 & 9,599 & 43.7 \\
\hline Totales: & 562,516 & 50,209 & 271,586 & 321,795 & 57.2 \\
\hline
\end{tabular}

Las características culturales de esta enorme población indígena de 321,795 habitantes, presenta una amplia gama de modalidades que van, desde las de tipo tribal que se encuentran entre los Mayas de la parte central de Quintana Roo, hasta las de carácter semi-urbano que se obsevan en las comunidades de Yucatán. (Redfield, 1944.)

Los Mayas de Quintana Roo que, por varias generaciones, se mantuvieron en estado de rebeldía, comienzan a perder su oislamiento y, con ello, su antigua autonomía. Sin embargo, la pequeña sub-tribu de X-Cacal, todavía se aferra a su antigua organización teocrática-militar, en la que, el control del Gobierno, está en manos de sacerdotes y Jefes con grado militar. Sus pueblos dependen de una cabecera que sirve de Santuario, en el que está el Templo Mayor y los edificios que sirven de cuarteles a los varios destacamentos de nativos que se turnan el servicio de guardia de ese lugar. En general, la religión de este pequeño grupo está fuertemente influida por las ceremonias y creencias del ritual católico, no obstante que todo el personal que dirige misas, rosarios y demás, es autóctono del lugar. Es hasta ahora que una Misión de sacerdotes jesuitas trata de ganar su confianza.

En las aldeas más aisladas de Yucatán todavía se pueden observar ceremonias paganas, como las relativas al culto de la 
lluvia, que se practican frente a altares rústicos que se improvisan en las milpas o en algún claro del bosque. La más importante de estas ceremonias es la llamada Cha-Chac por la que se invoca el favor de los Chaques o dioses de la lluvia en el momento en que la milpa está a punto de alcanzar su mayor desarrollo. El oficiante recibe el nombre de $\mathrm{H}-\mathrm{Men}$ ("El que sabe"), el cual es una especie de sacerdote-Chaman que tiene a su cargo todo lo relativo al culto de los dioses paganos; además, hace de curandero y de adivino. A medida que los pueblos se acercan a las carreteras y vías de ferrocarril, pierden su conservatismo y se alejan de los usos, costumbres y creencias de Ia antigua tradición Maya.

El maíz sigue siendo la base de la economía indigena, hasta el punto que, un $75 \%$ de la dieta regional está basada en ese cereal. En Quintana Roo, los indios suelen participar en la extracción del chicle que, como se sabe, es la resina deshidratada mediante cocción del árbol llamado chicozapote; de aquí obtienen el dinero que les permite comprar lo que necesitan del exterior. En Yucatán, buena parte de la población depende de la industria del henequén, fibra de la que se hacen artículos diversos, especialmente del ramo de jarciería. En Campeche, donde el cultivo del maíz carece de tierras adecuadas, la economía indígena se auxilia con el ejercicio de algunas artesanías, entre las que destacan las del sombrero de jipi y de artículos de palma (cestos, escobas, sombreros, etc.), de cerámica, así como de la cría de abejas que, a últimas fechas ha alcanzado gran desarrollo.

En suma: puede decirse que, dado el incremento que va teniendo en la Península la construcción de carreteras, el proceso de aculturación se va acelerando en detrimento de los viejos modos de vida que se identificaban con la comunidad indígena, de carácter tradicional y subdesarrollado. Nada indica mejor el ritmo de este cambio acelerado que el decremento del índice de monolinguismo, pues de 227,883 individuos que ignoraban el español en 1910, ahora sólo han de quedar unos 25 o 30 mil; el último dato exacto de que disponemos, fue el del censo de 1950 que ya dejamos asentado. (Para más datos sobre la etnografía y demografía de la Península, véanse: Redfield y Villa Rojas, 1934; Villa Rojas, 1945; León Portilla, 1959; Alanís Patiño, 1959.) 


\section{Los Chontales.}

De acuerdo con los datos asentados por León Portilla siguiendo el censo de 1950, la población de origen Chontal alcanzaba la cifra de 24,703 inidivduos, de los que, apenas unos 1,539 ignoraba el español; en la actualidad, ya este número ha de haber bajado en forma considerable, dado que la región en que residen ha recibido un fuerte estímulo por parte del Gobierno en todo lo concerniente a comunicaciones y obras materiales. Se trata, pues, de un grupo que ha quedado prácticamente incorporado a la vida nacional.

No obstante lo anterior, la región que habitan sigue presentando características de atraso y pobreza, así como algunos rasgos de las viejas costumbres indígenas. Esta región corresponde a la parte central del Estado de Tabasco y abarca los Municipios de Nacajuca, Centro, Centla, Jalpa, Tacotalpa y Macuspana. Desde luego, la parte más densamente poblada es la que se extiende de Villahermosa hacia la faja costera, especialmente la que comprende el Municipio de Nacajuca donde están asentados los pueblos de Tucta, Mazateupa, San Isidro, Tecoluta, Guaytalpa, San Simón y Tapotzingo (Margaret Harris, 1946, pág. 248). Esta región costera es atravesada por varias corrientes fluviales que, por falta de declive, fácilmente se desbordan al llegar la temporada de lluvias con marcas de precipitación anual que fluctúan entre 2,500 mm. y 3,000 mm. Así es que, de septiembre a noviembre en que llueve más, pocas casas escapan de inundarse, por lo menos, parcialmente; los nativos ya están tan acostumbrados a estas inundaciones periódicas, que han optado por levantar unos veinte centímetros el fogón del suelo, para que así no se los apague el agua. Las condiciones resultan menos penosas hacia el rumbo de Macuspana, cercano a Chiapas, donde ya se encuentran lomeríos y mejores condiciones de suelo. El clima fluctúa alrededor de los $38^{\circ}$ C. en Verano.

Por lo que toca a la lengua, existen, por lo menos, dos variantes dialectales: una que se habla en la zona costera y otra que se habla en las cercanías de Macuspana; esta última es llamada Yocotán por los propios nativos de la región (Blom \& La Farge, 1927, vol. II, págs. 487-504). Este dialecto de Macuspana es el que cuenta todavía con mayor número de hablantes.

La economía es predominantemente agrícola, con maíz y 
frijol como cultivos principales. La zona de la costa tiene como auxiliar la industria del sombrero de palma, artículo muy solicitado en la región por su calidad flexible e impermeable; estos sombreros son de copa alta y ala angosta, recibiendo en la región el nombre de "chontales". También hacen capas del material que, por su impermeabilidad resultan muy útiles en tiempo de lluvias. También obtienen recursos pecuniarios sirviendo de peones en los ingenios de caña o en las grandes plantaciones de plátano, café o cacao.

No obstante la buena calidad de la tierra y las oportunidades de trabajo que allí se encuentran, la población vive en condiciones de aguda pobreza, la cual ha sido atribuida a enfermedades endémicas, indolencia e inclinación al alcoholismo. James E. Russell que estudió las condicónes sanitarias de la zona costera, nos informa que:

"La falta de dinero significa falta de medicinas y atención médica. Muchos de los hombres, en vez de trabajar el día completo como era de esperarse, comienzan a hacerlo a las 6 de la mañana, para interrumpirlo a las 7:30 a. m., y tomar un breve descanso. Luego continúan hasta llegar el mediodía en que dan por terminada la tarea.

"Es cierto que el sol resulta quemante de 11 a. m. a 3 p. m., y que eso justificaría la suspensión del trabajo a tales horas, pero, ya en la tarde, mucho podría hacerse. En vez de ello, los hombres prefieren pasarse el tiempo en la hamaca, o platicando o, lo que es peor, emborrachándose en la plaza. El resultado es la pobreza predominante, ya que no producen lo suficiente para hacer frente a emergencias imprevistas." (1947, págs. 319-20.)

Esta condición de pobreza se deja ver, no sólo en su mal estado de salud sino, también, en sus chozas, ropas y utensilios domésticos. Las chozas, casi siempre húmedas, son de palma y bajareque, sin ventanas y pisos de tierra apisonada. El traje regional que prevalecía hasta hace una generación, ha sido sustituido por prendas similares a las que se ven en la ciudad: pantalón y camise corta en los hombres y vestidos sencillos en la mujer; por lo común, van descalzos. El equipo deméstico es sumamente reducido y sencillo: el metate, el comal y el fogón constituyen la parte esencial de la cocina, en la que existen, también, una que otra mesita y rústicos asientos. Los adultos duermen sobre tapescos improvisados de tablas y troncos que recubren con un petate, en tanto los chamacos prefieren la hamaca. 
En sus comidas predominan las tortillas y el posole; las primeras se hacen del mismo modo que en Yucatán: torteándolas sobre hoja de plátano. Tienen otra bebida compuesta de cacao molido mezclado con posole; esta bebida es muy común y se emplea tanto para agasajar a las visitas como para alimento de la familia a toda hora del día. Landa (cap. XXI) la menciona diciendo: "Que hacen del maíz y cacao molido una manera de espuma muy sabrosa con que celebran sus fiestas." También tienen la bebida fermentada llamada balché, aunque preparada de modo distinto que en Yucatán, pues, la fabrican con agua, caña de azúcar, "palo-guarapo" y maíz (Basauri, tomo II, pág. 129). Cabe decir que esta bebida se asemeja más a la chicha de los indios de Chiapas que al balché de los Mayas, el cual se prepara con agua y miel en la que se deja fermentar por varios días la corteza machacada del árbol llamado balché. Es de añadirse que, aunque en algunas rancherías y pueblos disponen de ganado para comerciar, nunca aprovechan la leche de vaca debido a que les causa marcada repulsión; de otra manera, podrían aliviar la desnutrición que se nota en los niños.

En algunos aspectos del ciclo de vida se puede percibir hasta hoy el sello de la antigua tradición indígena. Así, al dar a luz, la mujer adopta la llamada "posición Nahoa" que consiste en ponerse de cuclillas en el suelo, sobre un petate u hojas de palma, sujetándose de una viga del techo mediante una reata que le pasa bajo las axilas; el esposo debe estar presente para ayudar a la mujer y sostenerla entre los brazos. La partera es alguna mujer del lugar con experiencia en estas cosas. Si la criatura es mujer, se le corta el cordón umbilical apoyándolo sobre un pedazo de carbón encendido y, si es hombre, apoyándolo sobre una mazorca. De este modo se asegura que la mujer será buena cocinera y, el hombre, buen agricultor; el corte del cordón se hace con un cuchillo cualquiera. (Harris, ibid., pág. 251).

En lo que toca a religión, sobresale la influencia del culto católico, aunque dejando entrever la presencia ocasional de creencias y prácticas indígenas. Así en la fiesta patronal de Tapotzingo (cercano a Nacajuca), se dedica el primer día con su noche a tocar los tambores (dos chicos y uno grande) y un flautín en honor de los dioses de la lluvia, a quienes se invoca para lograr buenas cosechas. El segundo día tiene lugar el bai- 
le, el cual presenta cierta semejanza con la jarana yucateca; inclusive en la costumbre de premiar a las buenas bailadoras poniéndoles el sombrero del hombre, prenda que luego se rescata a cambio de unos 30 o 50 centavos. Por lo general estas fiestas duran tres días, durante los cuales el ajetreo mayor es en la Iglesia donde tienen lugar misas, rosarios y funciones religiosas.

Según el estudio ya citado de Russell, las enfermedades predominantes en la región son: la disentería, el paludismo y la tuberculosis. La falta de médicos obliga al empleo de remedios tradicionales, así como al ejercicio de brujos y curanderos.

Cabe decir que todavía no se cuenta con un estudio adecuado de la región, salvo el de Scholes y Roys (1948) que se refiere a la etnografía antigua de toda esta parte del Area Maya.

\section{Los Lacandones.}

Este es el grupo más primitivo, aislado y pobre de todos los que habitan el sureste de la República. Ocupan la zona oriental del Estado de Chiapas, de clima lluvioso y cálido, de vegetación boscosa y siempre verde. Sus pequeñas rancherías (llamadas caribales), de sólo dos o tres familias, se asientan en las márgenes de diversos ríos y arroyuelos que van a desembocar al Usumacinta, de caudalosa corriente.

Siguiendo los datos últimos de Gertrude Duby, por que tanto tiempo ha recorrido la región, los miembros de este grupo apenas llegan a unos 158, aparte de unos seis que residen del lado guatemalteco. Es tal su condición de atraso y abandono que, al decir de la autora citada: "Si no llega pronto a los Lacandones una ayuda, desaparecerán en pocos años." (Blom y Duby, 1957, pág. 205). El idioma que hablan es una variante dialectal del Maya de Yucatán. Casi todos son monolingües; los pocos que se pueden entender con los de afuera, no conocen sino unas cuantas palabras o frases de español.

No obstante ser tan pocos, están distribuidos en una enorme superficie boscosa que abarca de 10,000 a $15,000 \mathrm{Km}^{2}$. Se agrupan en tres núcleos principales, que son: los de la zona Norte, donde están las lagunas sagradas de Noh-há, Metsabok, Peljá y otras, los cuales tienen ya contactos frecuentes con los finqueros, monteros, comerciantes e, inclusive, con Misioneros evangelistas que, desde veinte años tratan de convertirlos al 
nuevo culto; el grupo cercano a la laguna de Lacanjá y, finalmente, el grupo de San Quintín, cercano al río Jataté que tiende a desaparecer; no sería difícil que, al publicarse estas notas, ya hubiese acabado totalmente por muerte o migración de sus componentes. Amram (1942, págs. 15-26), que ha visitado varias veces a esos núcleos, hace un relato patético sobre la facilidad con que se desintegran sus caribales o caseríos debido a las causas antes citadas; lo más triste es que, aparte de la gradual disminución de sus miembros, ya han perdido todo sentido de comunidad e, inclusive, de las normas éticas propias de la familia que, hasta hace una o dos generaciones guiaron su existencia; los casos de incesto entre hermanos y de padres con hijas han comenzado a registrarse.

Existen algunas variaciones culturales entre los tres núcleos citados y, también, diferencias físicas, según observaciones de Georgette Soustelle en su visita a la zona en 1936. Comparando las medidas de los del Norte (o Noroeste como asienta ella) con los del Sur, la citada investigadora obtuvo las medidas que siguen:

Grupo del Noroeste

156.6

83.36

72.03
Grupo de San Quintin

152.3

86.1

65.

\section{A esto añade que:}

"En los dos grupos, la piel es de color moreno claro, los ojos de igual color y ligeramente oblícuos; la pilosidad del rostro y del cuerpo bastante escasa; los cabellos son negros y ligeramente ondulados. Encontré coexistiendo en los diversos grupos, dos tipos físicos distintos: uno, de individuos de cara grande y, otro, de rostro más largo y más fino." (1959, págs. 143-4.)

Es posible que esta diferencia física se deba, por lo menos en parte, a que, además de los Choles que habitaron originalmente la región, se agregaron, en los siglo XVII y XVII, grupos Mayas de Yucatán y del Peten que rehusaban someterse al dominio español.

Tanto en su cultura material como en los rasgos más relevantes de su organización social y religiosa, los Lacandones dejan ver, con marcado vigor, la persistencia de la antigua tradición Maya; esta condición de supervivencia se pudo man- 
tener, gracias a que el grupo logró mantener su autonomía a través de todo el régimen colonial e, inclusive, hasta nuestros días.

Las chozas, de palma y troncos, presentan un aspecto endeble y descuidado, con los lados al descubierto o, a lo más, protegidos por una enramada de palmas y ramas; otras veces, esta protección se logra dejando demasiado bajas las dos alas que forman el techo; en realidad, viven casi a la intemperie y en promiscuidad con cerdos, perros y gallinas.

El mobiliario es de lo más rústico y simple, pues, consiste en objeto de barro, jícaras, troncos de árbol como asientos y ramas diversas que se usan como ganchos para colgar lo que se ofrezca, así como charolas de liana entrelazada que se sujeta del techo mediante cordeles y les sirve para poner sus comestibles fuera del alcance de los animales. El comal, cántaros, ollas y otras vasijas de barro, son de manufactura local, frágiles y hechas con tosquedad. Desde luego, el elemento más importante y más usado de los que integran el mobiliario es la hamaca, hecha de mecate grueso y tejido bastante en forma de red; es sumamente estrecha y poco confortable, inclusive para personas acostumbradas a dormir en las hamacas de los Mayas de Yucatán, que son amplias y de tejido más cerrado y fino.

El traje es, también, bastante simple: los hombres usan, únicamente, una ancha túnica que les llega a las rodillas; el cuello y las mangas son simples agujeros, sin forma ni adorno especial; la tela empleada es tejida por la mujer en el viejo telar de cintura, usando para ello algodón que cultivan ellos mismos. Hasta hace algunos años era común el uso del taparrabo o kaxnak descrito por Tozzer en 1907 (pág. 29), el cual consistía en una tira de manta, larga, que se pasaba entre las piernas, dando luego vueltas en la cintura y dejando caer un extremo al frente y otro hacia atrás. También van desapareciendo las vestimentas hechas de fibra de maguey o de la corteza del árbol llamado majagua. El mismo Tozzer informa que no se acostumbra el uso de sombreros o alpargatas, tanto en hombres como en mujer; sin embargo, hoy en día, ya suelen llevar alpargatas cuando van al trabajo.

El traje de la mujer es casi igual al del hombre en lo que se refiere a la túnica o poncho; usan, además, una ancha enagua que llevan debajo y que se sujetan a la cintura mediante una tira o faja (ujechehinok). Ambas prendas se confeccionan con manta comercial que obtienen de la gente de afuera. 
Son muy dadas a los adornos, especialmente de collares que hacen ellas mismas con semillas silvestres o, también, de manufactura comercial hechos de cristal o de plástico. (Para más datos sobre la cultura material, véase Jacques Soustelle, 1937).

Por lo que se refiere a su estructura social, ahora en plena desintegración, estaba apoyada en la existencia de clanes exogámicos patrilineales que, a su vez, se dividían en linajes geográficamente localizados; este tipo de estructura fue el que existió entre los Mayas de la antigüedad. Tozzer no llegó a penetrar hondo en este aspecto de la cultura por lo que sus datos resultan un tanto deficientes. Afortunadamente, existe ya material comparativo que nos permite confirmar lo antes asentado (Villa Rojas, 1947). Presentando en forma esquemática los elementos de tal organiación, tenemos los clanes y linajes distribuidos del modo que sigue:

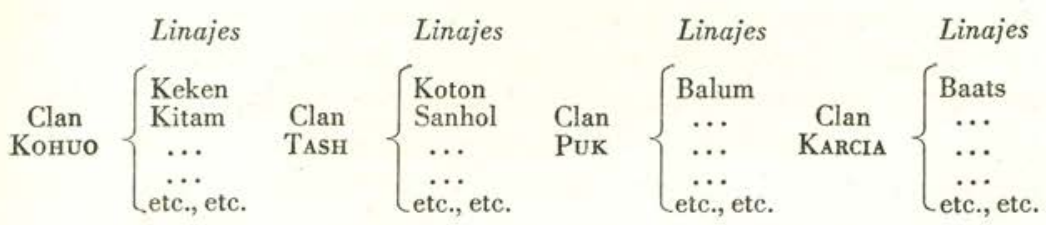

En total, Tozzer anotó dieciocho linajes a principios de siglo y Soustelle descubrió otros dos en 1936; así es que, en conjunto, existieron veinte linajes distribuidos en cuatro clanes. Como es de esperarse, la terminología de parentesco era del tipo clasificatorio, según el cual se aplica el mismo término a más de una categoría de parientes. Así, los términos hermano, hijo, padre, etc., se hacen extensivos, según la edad del que habla, a todos los otros miembros del clan.

Como ya quedó expresado, los miembros de cada linaje estaban concentrados en zonas determinadas. De este modo, las familias del linaje Maash (mono), tienen sus parajes o caribales en las cercanías del lago Pet-há; las de los linajes Koton y Sanhol agrupadas en la región de la laguna de Anaité y, así, con las familias de los demás. Casi todos estos nombres de linajes corresponden a animales que fueron los totems de los mismos; es decir, cada linaje se consideraba ligado por lazos de parentesco místico con el animal cuyo nombre llevaba; este rasgo de su organización clánica se ha venido perdiendo y, ya desde el tiempo de Tozzer, al iniciarse este siglo, se 
había debilitado mucho. De acuerdo con los datos de Tozzer, la situación entonces existente sobre totemismo era la que sigue:

"Los nativos hablan de los nombres de animales citados como in yonen, es decir, 'mi pariente'; de modo que parece haber una íntima conexión entre todos los individuos del mismo nombre animal y el animal mismo.

"...cualquier que haya podido ser la idea del totem y de las prácticas totémicas referentes al animal, han sido ya perdidas y no queda otra cosa que el simple nombre animal de las divisiones mencionadas.

"...Parece ser práctica común la de mantener en cautiverio los animales conectados con la localidad en un sentido totémico. En esta forma, se pudieron notar monos, torcazas y pájaros diversos retenidos como animales consentidos, especialmente por las mujeres." (1907, págs. 41-2.)

Años después, Soustelle encontró que los indígenas se comían a estos sus totems, y al indagar sobre el punto con un miembro del linaje Maax (mono) el indio le contestó: "Es cierto que el mono es mi 'pariente' pero, de todos modos, me gusta comerlo" (1935, pág. 336). Así es que, prácticamente, esto del totemismo entre los Lacandones es cosa del pasado.

En concordancia con su sistema de parentesco, estos indios usan nombres que señalan su linaje, la familia a que pertenecen y el orden de nacimiento; así, al hijo mayor se llama Kin (Sol); al siguiente, Chan-Kin (Pequeño Sol), y así como otros, correspondiendo éstos al linaje Baats (mono); otros nombres, como Kay-Yum y Na-Kay-Yum, corresponden al linaje Sanhol, que es otra especie de mono. No es, sino en estas últimas décadas, que los monteros de afuera que recorren la región les han puesto nombre modernos, tales como "Obregón", "Carranza", etc., etc.

Por lo que se refiere a su forma de Gobierno, ya se ha perdido por completo, pues, en la actualidad, cada familia se rige como puede sin guardar respecto a Jefes o autoridad tribal alguna. La forma como se regían en tiempos pasados, puede verse en Ximénez, Villagutierre y otros cronistas de los siglos xvII $y$ xviII. Tozzer mismo, nos dice a este respecto que: "Hay poca o ninguna necesidad de acción concertada o de gobierno central entre los Lacandones, viviendo como lo hacen en comunidades autosuficientes" (ibid, págs. 43-4).

Es en el aspecto religioso que la cultura de los Lacandones mantiene todavía cierta vitalidad, mostrando, en su forma más sencilla, las viejas prácticas y creencias de los Mayas antiguos. 
La mayor parte de sus ceremonias tiene por objeto invocar el favor de sus dioses paganos para curar enfermedades o evitar posibles infortunios. En sus llamadas ermitas, que son simples cobertizos de palmas, se hacen las ofrendas, rezos y cantos a tales dioses, representados por los rostros modelados en el exterior de las vasijas de barro que les sirven de braseros. Se considera que estos rostros son los intermediarios entre los hombres y los grandes dioses que gobiernan el mundo, tales como Nohoch-Chac-Yum, Itzm-Noh-Kú, Kay Yum, Sakapuk y otros. Algunas familias, conservan, en grạn secreto, ídolos pequeños de jade, a los que consideran sus protectores inmediatos. En sus ceremonias, la familia deposita el ídolo que le corresponde en el fondo de algún incensario $\mathrm{y}$, sobre él, quema el copal. Estos ídolos son transmitidos de una a otra generación, pues, se cree que un ancestro de la familia visitó el lugar de ese dios y obtuvo de él su efigie grabada en jade. (Tozzer, 1907, págs. 87-8). Es de hacerse notar que estos incensarios, todavía en uso entre los Lacandones, son casi idénticos a los hallados por Gann (1918, págs. 120-1) en Santa Rita, Icaiché y otros lugares de Belize y Quintana Roo.

Aparte de los ídolos citados, los Lacandones suelen hacer viajes de varios días hasta la gran ciudad antigua de Yaxchilán, con objeto de recoger, en el interior de sus santuarios, algunas piedrecitas que luego ponen en sus braseros como objetos altamente sagrados (Blom \& Duby, 1957, pág. 198). Lástima que, la falta de espacio, nos obligue a dejar aquí el tema fascinante de las viejas supervivencias que aún se conservan en los dioses, ritos y ceremonias de estos indígenas. Sin embargo, consideramos haber dicho ya lo suficiente para dar una idea del estado cultural en que se encuentran en la actualidad, mostrando el conservatismo excepcional en que se han mantenido.

\section{Los Choles.}

Las comunidades que constituyen este grupo están situadas en el extremo noreste del Estado de Chiapas. Según el censo de 1950, su población comprendía 31,139 habitantes, de los que 18,898 ignoraban el español. La totalidad de esta población monolingüe está concentrada en los Municipios de Tumbalá, Sabanilla, Tila y Salto de Agua; los otros tres Municipios en los que se habló esa lengua, Palenque, Catasajá y La Libertad, 
ya la han olvidado en favor del español. La región que ahora habitan estos indios es bastante quebrada, con alturas máximas de 1,200 y 1,300 m. s. n. m. en los puntos que corresponden a las cabeceras de Tila y Tumbalá, respectivamente; ya hacia el Norte, rumbo a Tabasco, el nivel desciende marcadamente, hasta llegar a la zona de llanuras. En lo general, el clima es más bien cálido y húmedo; la estación de lluvias, larga y copiosa (2 mts.), y la vegetación, densa y lujuriante.

No existe, hasta el presente, ningún estudio adecuado sobre la etnografía de estos indígenas, pues las notas de Basauri (1940, vol. II, págs. 135-150), y las de La Cerda Silva (1957, págs. 495-506) resultan sumamente breves e incompletas. Quien esto escribe tuvo oportunidad de visitar la región en 1938, recorriendo a caballo desde Tila hasta Salto de Agua, pero sin detenerse lo suficiente en ningún lugar, de modo que nuestro conocimiento directo de sus modos de vida es bastante limitado. Desde luego, podemos decir que los indios que conocimos, se mostraron hospitalarios, laborios่os, limpios, pero poco comunicativos. El propio pueblo de Tila se ve densamente poblado, con un excelente edificio municipal y una magnífica iglesia; en ésta se guarda la milagrosa efigie del "Cristo Negro de Tila" que goza de gran renombre a través de toda la región. Su fiesta anual se ve concurrida por miles de peregrinos, los cuales, con su contacto, han contribuido a que la cabecera se vea menos abandonada; de todos modos, su aspecto, es todavía marcadamente indígena. Como simple índice de esta condición, es de citarse que, por el tiempo de nuestra visita, el Municipio contaba con una población de 13,530 habitantes, de los que 9,746 desconocían el español.

Estos Choles son los mismos que hallaron los españoles en 1529 residiendo en el extremo sureste de la zona Lacandona; de hecho, fue a ellos a quienes primero se aplicó el término $\mathrm{La}$ candón, corrupción de Lacam-tun (Gran Roca), por razón de que así se llamaba el pueblo principal en que vivían, asentado sobre un gran peñón enmedio de la laguna que ahora se nombra de Miramar (Villagutierre, 1933, Libro 1, Cap. XI, página 60). Más adelante, en 1564, el abnegado misionero fray Pedro Lorenzo, logró persuadirlos y fundar con ellos Tila, Tumbalá y Palenque, poniendo a otros en Bachajón y en Ococingo. (Ximénez, 1930, Libro IV, cap. 58, pág. 252). Su catequización fue intensa en las primeras décadas de su traslado; ya 
luego, se les abandonó, volviendo a su rusticidad, favorecida por lo anfractuoso del terreno y su lejanía de los centros de difusión cultural. Salvo uno que otro cura que solía estar con ellos de vez en cuando, no tenían otros contactos con el mundo exterior. A esto se debe que, cuando Stephens (1949, Vol. II, pág. 223) pasó por Tumbalá, a principios de 1840, pudo decir que: ". . . era el lugar más salvaje y extraordinario que jamás había visto... rodeado por todas partes de montañas altísimas, casi inaccesibles, y barrancas profundas en las que se veían las milpas de los indios, los cuales seguían viviendo casi en las mismas condiciones que al llegar los españoles." Aún dos décadas después, cuando Désiré Charnay pasó por allí, tuvo la misma impresión, añadiendo que:

"Las únicas autoridades del pueblo son el 'gobernador', encargado de la recaudación de los impuestos; comúnmente es un indígena de la localidad nombrado por elección y cuyo poder, completamente ficticio, consiste en recibir las órdenes del cura; después, el propio cura; en él coinciden todos los poderes: es sacerdote, juez, rey, dueño absoluto... todos lo respetan; su palabra es la del oráculo y sus decisiones tienen fuerza de ley. El distribuye las recompensas y los castigos y éstos son aceptados sin protesta. Las únicas penas son los azotes o la cárcel. Es una interpretación simple y primitiva de la ley, que alcanza a todos los delitos. El número de azotes oscila entre doce y ciento cincuenta pudiendo, en este último caso, ocasionar la muerte del reo." (1956, pág. 129.)

Con estos antecedentes, el lector puede ya comprender que esos Choles que habitan la parte montañosa, comienzan apenas a familiarizarse con los usos y modos de la vida moderna; el número de analfabetos es todavía bastante elevado, así como el de individuos incapaces de comunicarse con los de afuera por no saber español. Sin duda que todavía han de conservarse entre ellos muchas de sus viejas costumbres, prácticas y creencias, tal como acontece con sus vecinos inmediatos, los Tzeltales y los Tzotziles; no existiendo, sin embargo, conocimiento adecuado sobre ellas, habremos de limitarnos, en los párrafos que siguen, a presentar unas cuantas notas sobre los aspectos más generales o accesibles que los caracterizan en la actualidad.

Desde luego, su cultura material se mantiene apegada a la tradición indígena. Sus chozas son de palma o zacate, lados de bajareque y suelo de tierra apisonada; algunas de estas chozas, como las de Tila, están construidas con esmero; son de cuatro aguas, largas ( 6 a 8 metros por 4 de ancho), con puertas 
al frente y en su parte posterior y una o dos ventanas pequeñas; muchas se ven blanqueadas con cal en su exterior, lo que les da grata apariencia. Esta pieza larga cumple las más diversas funciones: sala, dormitorio, cocina, comedor y bodega; en algunos casos, se tiene un pequeño anexo que sirve de cocina. Otros anexos que suelen tener son el gallinero y el chiquero. En Tila, las casas están distribuidas en calles largas que siguen el contorno y desnivel del cerro en que están asentadas; subiendo por ellas, me dio la impresión de estar entrando a una fortaleza. En otros lugares, como en Tumbalá, las chozas son más bien cuadradas, de construcción menos sólida y apariencia más rústica. Algunas tienen cobertizos al frente y detrás formados con las salientes del techo que se proyectan uno o dos metros. En la zona caliente, se suprimen las paredes de barro y se deja sólo el otate o varillas entrelazadas.

En armonía con la choza está el mobiliario, en el que ocupa lugar principal, por su mayor variedad, el referente a la cocina: banco, metate, vasijas de barro, de formas y tamaños diversos, jícaras, calabazos, así como tazas, platos, cucharas, cubetas y otros objetos de peltre o metal. En la parte que corresponde a sala y dormitorio, se ven "tapextles" o camas toscas de troncos y varillas, hamacas, petates, cajones, redes diversas, ganchos y cuernos de venado que sirven de perchero. También se observan, desperdigados por dondequiera, los instrumentos de labranza: arado de madera, azadón, machete, coa, hacha, cuchillos, pala y el espeque o palo puntiagudo para sembrar; algunos tienen, además, en la parte de afuera, trapiches primitivos para moler la poca caña que cultivan. También es frecuente encontrar el telar de cintura que todavía se usa a través de la región.

La indumentaria sigue el mismo patrón de los otros pueblos circunvecinos habitados por Tzeltales de "tierra caliente"; la del hombre se compone de calzón corto, que llega hasta la rodilla, y camisa de forma parecida a la de la "guayabera" que se usa en Yucatán; es decir, suelta y de manga larga. Ambas prendas son de algodón. Llevan, además, sombrero de palma y, ocasionalmente, alpargatas muy simples amarradas con cordeles. Cuando van de viaje, llevan una o dos bolsas de yute en las que ponen todo cuanto puedan necesitar; a esto añaden su machete, su cobija y un palo puntiagudo, a manera de bastón, para ayudarse en los pasos malos o resbalosos que abundan 
por los cerros. Por lo que se refiere a la mujer, lleva camisa de algodón, de manga corta, adornada de tiras, cintas o bordados vistosos en el cuello y en las mangas; la enagua, es de manta gruesa, con pliegues que forman un pequeño bulto al frente a la altura de la cintura; se dice que, en las casadas, la enagua ha de ser azul y, én las solteras, blanca. El pelo se lo adornan con listones de color; usan, además, aretes y numerosos collares de cuentas de cristal o pasta. Por lo general, van descalzas. En sus viajes, se cubren las cabezas con una manta doblada. Como es natural, el traje varía en calidad de acuerdo con las posibilidades económicas de la persona; por lo común, estas indias se ven limpias y atractivas.

La agricultura constituye la base de su economía; aparte del maíz, frijol y chile, cultivan algo de café, caña de azúcar, arroz y papa. La cría de cerdos es otra de sus ocupaciones importantes, pues de ella obtienen buena parte de sus entradas pecuniarias. En casos de necesidad, se van de peones a las fincas de café, a los campamentos chicleros o a las fincas de la región de Salto de Agua. Ocasionalmente, salen de caza, empleando para ello escopetas y trampas.

El noviazgo y el matrimonio siguen las reglas o costumbres ya conocidas para otros grupos indígenas, en el sentido de ser los padres quienes se encargan de los trámites preliminares hasta dejar instalada a la pareja. Ya se ha perdido toda traza de la organización unilateral que aún se observa en otros grupos de los Altos de Chiapas. En toda familia ha de haber un encargado varón que la represente y, los miembros de más edad disfrutan de especial respeto y estimación de los suyos.

En lo que toca a religión, muestran especial devoción al ya citado "Cristo Negro de Tila"; siguen los preceptos de la Iglesia católica, sin por ello olvidar por completo las creencias y prácticas de su antigua religión. Altas cumbres, peñascos y cuevas, siguen siendo lugares de significación mística, por suponerse que en ellos habitan seres y espíritus que manejan las lluvias, los vientos y los rayos. También subsiste la creencia en brujos y naguales. Los eclipses provocan alarma, ya sean de sol o de luna, por suponerse que el astro puede desaparecer ante el ataque de seres o animales desconocidos; para ahuyentarlos, acostumbran hacer gran escándalo, tocando el cuerno, así como latas, cajas, tambores y aún disparando sus escopetas. De la Cerda Silva (1957, pág. 504) informa que: "En algunos 
lugares de la Sierra aún guardan y veneran ídolos pequeños de piedra... a los cuales les queman incienso, les encienden velas y les hacen ofrendas de flores y frutas y especialmente de jarros con látex de chicle."

En suma: para fijar en términos de brevedad la posición cultural de los Choles, podemos decir que se trata de un grupo bastante conservador, apegado a su lengua, con formas de vida marcadamente indígenas, aunque influidas por las enseñanzas de los primeros misioneros católicos. En fechas recientes, a partir de 1943, han recibido, también, la influencia de misioneros protestantes de origen norteamericano que se han establecido en el pueblo de Tumbalá, los cuales han logrado tener bastante éxito en su labor de proselitismo. En lo general, son indios laboriosos, limpios, hospitalarios y agradables.

\section{Tzeltales y Tzotziles.}

Por razón de las similaridades que presentan estos dos grupos en lo que toca a su ambiente natural y cultural, los incluiremos en una sola sección indicando, cuando sea preciso, los puntos en que se diferencian.

Con excepción de los Mayas de Yucatán, estos son los grupos más numerosos de toda el área que venimos describiendo; sus formas de vida revelan todavía fuerte apego a sus viejas tradiciones, así como a su lengua. Las cifras que presentamos a continuación permiten entrever el grado de aislamiento geográfico y social en que se han mantenido, ya que, de otro modo, no hubiesen podido conservar tan alto índice de individuos incapaces de expresarse en español.

\section{POBLACION Y MONOLINGUISMO \\ (Censo de 1950)}

$\begin{array}{lcc} & \text { Habitantes } & \text { Ignoran español } \\ \text { Tzotziles } & 74,827 & 44,103 \\ \text { Tzeltales } & 48,279 & 31,856 \\ \text { Totales: } & \overline{124,106} & \mathbf{7 5 , 9 5 9}\end{array}$

Como punto de interés es de hacerse notar que, de 1930 a 1950, el número de hablantes monolingües del Tzeltal se mantuvo prácticamente el mismo, en tanto que el de los hablantes del Tzotzil aumentó en un $69.5 \%$; el dato es de verdad asom- 
broso, ya que ello indica la distancia que separa a esta región del proceso evolutivo que se observa en la Nación. (Sobre las cifras que aquí presentamos, véase León Portilla, 1959, páginas 64-5).

Tanto los Tzeltales como los Tzotziles tienen sus comunidades de mayor población en la parte más anfractuosa y quebrada del Estado de Chiapas, en la que cumbres, barrancas, canadas y voladeros, se suceden de modo interminable. Los puntos de mayor altura se encuentran, precisamente, en la zona central del Estado, donde sobresalen los cerros del Hueitepec (2,660 m. s. n. m.) y el del Zontehuitz $(2,858$ m. s. n. m. $)$. A partir de esta zona, el relieve desciende, especialmente en la parte del Norte, rumbo a Tabasco.

Esta diferencia de relieves da lugar a climas, vegetación y suelos distintos, con la consiguiente diferenciación de modos de vida. En la parte alta, anfractuosa y fría, residen los indios más conservadores y retraídos, en tanto que, en las tierras bajas, de menos barreras naturales y mayor número de gente mestiza, reside la población más accesible y hospitalaria. Como ya dijimos, la densidad de población es mayor en la parte alta, aunque el número de Municipios o comunidades resulta superior en las tierras bajas. De acuerdo con la lengua y la zona a que corresponden, los citados Municipios se distribuyen del modo que sigue:

MUNICIPIOS DE TIERRA CALIENTE

\section{Tzeltales}

Ococingo. (Incluyendo Sivacá.)

Citalá.

Guaquitepec.

Chilón. (Incluyendo Bachajón.)

Yajalón.

Altamirano.

Pinola. (Incluyendo Aguacatenango.)

\author{
Panteló. \\ Simojovel. \\ Huitiupan. \\ Amatán. \\ Pueblo Nuevo Solistahuacán. \\ Jitotol. \\ Bochil. \\ El Bosque. \\ Iztapa. \\ Zapotal. \\ Totolapa. \\ Venustiano Carranza. \\ La Concordia. \\ Socoltenango.
}

MUNICIPIOS DE TIERRA FRIA

Tenejapa.

Oxchuc.

Chanal.

Amatenango.

Teopizca.

Chamula,

Zinacantán.

Mitontic.

Larrainzar.

Chenaló.

Chalchihuitán. 
Es de indicarse la existencia de algunos lugares que, no obstante ser bien conocidos, no se incluyen en esta lista por ser simples Agencias Municipales de otros Municipios; tal es el caso de Cancuc, Tenango y San Martín (todos de tierra fría) que corresponden al Municipio de Ococingo que es de tierra caliente. Este Municipio, de más de $12,000 \mathrm{Km}^{2}$ de superficie, tiene parte de sus tierras en la zona fría y otras en la de clima caliente.

Desde el punto de vista cultural, estas comunidades o Municipios, presentan características tribales, ya que cada uno de ellos tiene su propio territorio, forma dialectal que le es peculiar, así como indumentaria, sistema de parentesco, organización político-religiosa, recursos económicos y otras expresiones culturales que distinguen unas de otras. Inclusive en el aspecto somático existen variantes que dan individualidad al tipo físico de cada comunidad; este simple dato nos da idea de los siglos que han pasado desde que tales comunidades quedaron organizadas en grupos cerrados de escasa mobilidad social y protegidos por barreras montañosas que los hicieron quedar en aislamiento. (Para más datos sobre esta diferenciación somática, véase Frederick Starr, 1902).

Estas unidades sociales que ahora representan dichas comunidades, no son sino variantes locales de un patrón cultural que, posiblemente, abarcó todos los Altos de Chiapas al amalgamarse las costumbres prehispánicas con las importadas por frailes y encomenderos en el siglo xvi. Como tales comunidades presentan en la actualidad estados diversos de aculturación, los rasgos que una vez las caracterizaron, se van borrando al contacto de nuevas ideas, costumbres e instituciones. Es así como, en unas todavía existe la institución del Calpulli, así como las de clanes exogámicos patrilineales que, a su vez, se subdividen en linajes, con su respectiva terminología clasificatoria; formas de control social basadas en el nagualismo y Consejos de ancianos. En otras, existe una división dual de la comunidad con práctica de la endogamia en cada una de ellas, pero sin clanes ni linajes; en otra más, el sistema de parentesco es bilateral y la comunidad se divide en barrios que, en algunos aspectos, se asemejan al Calpulli. Por último, existen unas cuantas en proceso avanzado de aculturación (tales como Soyatitán, Socoltenango y otras) donde las costumbres ya son práctimamente iguales a las de cualquiera otra comunidad mestiza o "ladina" 
de la región; en éstas, ya queda poco de la lengua aborigen y del antiguo modo de vestir que identificaba a los indígenas.

Las variaciones de indumentaria constituyen el más importante elemento de diagnóstico dentro del mosaico de culturas que forman las diversas comunidades. Dado que existe una variante local para cada comunidad, es posible identificar el lugar de procedencia de cualquier nativo con sólo observar su modo de vestir.

Todas las variantes existentes quedan comprendidas dentro de un pequeño número de prendas que son las mismas para toda la zona de los dos grupos que venimos presentando y que consisten de las que siguen: camisa y calzón de manta; cinturón rojo de lana o algodón; poncho o cotón de lana; sombrero de palma y sandalias de cuero. Por lo que toca a la mujer, sus prendas son las siguientes: nagua de manta gruesa y color azul oscuro, blusa o huipil de manta, holgado y largo; faja de lana roja; toca de manta o lana que se lleva doblada en la cabeza; aretes y collares de cuentas de cristal a los que, en veces se añaden monedas de plata de México o Guatemala. Por lo común, van bien peinadas y se adornan el cabello con un listón rojo de lana. No usan sandalias de ninguna clase, ni cuando van de viaje.

Con ese juego de prendas cada Municipio ha hecho un arreglo típico que lo caracteriza de modo especial. Así, las prendas masculinas distintivas del Municipio de Huistán son: sombrero pequeño de copa plana que semeja un plato y calzón corto y ancho, de forma peculiar a manera de un simple pañal cruzado entre las piernas. En cambio, en Tenejapa, se tiene como prendas características el sombrero de ala ancha y copa abultada que termina en punta, de la que penden, como adorno, listones de seda de múltiples colores; además, el poncho o chamarro de lana y listas claras y negras. Detalles similares se podrían citar para cada uno de los otros Municipios.

De modo igual que con el traje sucede con la habitación que, no obstante presentar el mismo tipo, exhiben variantes más o menos acentuadas de una comunidad a otra. Por lo general, son cuadradas, con techos de palma o zacate, de cuatro aguas, lados de bajareque y piso de tierra apisonada; carecen de ventanas y sólo tienen una puerta al frente. En algunos lugares, especialmente en los que corresponden a tierra caliente, comienzan a usarse ventanas pequeñas, casi como agujeros, que 
poco añaden a la ventilación e iluminación de la choza. En otros lugares que cuentan con bosques y, por lo tanto, con madera accesible, los lados de la casa son de tablas verticales y no de bajareque, y los techos se hacen de tejamanil. El uso del temazcal resulta bastante extendido en toda la región.

El mobiliario se reduce a lo más esencial: fogón de tres piedras, comal, piedra de moler, una o dos mesitas, banquitos de troncos ahuecados o sillas pequeñas adecuadas al tamaño de las mesas y buen número de jícaras, cántaros, tazas y ollas de barro de diversas formas y tamaños. Como objetos de innovación, comienzan a aparecer platos y artículos de peltre, así como el molino de mano para el nixtamal que, poco a poco, va sustituyendo al metate milenario. Completan- el mobiliario, ganchos que sirven de percheros, cajas de madera para guardar ropa, canastos, bolsas de fibra y charolas de bejuco que penden del techo y sirven para levantar artículos comestibles. En los lugares de tierra caliente (como Bachajón, por ejemplo) se añaden a estos muebles una mesita redonda llamada matz-juté que sirve para tortear y un banco de madera llamado ah-ken para apoyar el metate; estos dos artefactos son iguales a los que usan los Mayas de Yucatán. La cama es de tablas asentadas sobre dos travesaños que sujetan cuatro horcones clavados en el suelo. En lugares de tierra caliente, suelen verse hamacas.

Pasando ahora de la cultura material al aspecto social, es de asentarse que cada comunidad se compone de un pueblo que sirve de cabecera y de numerosos parajes o rancherías diseminados por el interior. En la cabecera se encuentran la Iglesia, el Cabildo, las tiendas y las pocas casas de "ladinos" o mestizos; existen, también, chozas de indígenas, pero en menor número, pues, la residencia habitual de ellos está en los parajes.

El gobierno municipal está constituido por autoridades de elección popular, las cuales tienen a su cargo todo lo referente a los asuntos de carácter estatal o federal; aparte de este gobierno constitucional, existe otro netamente indígena, integrado por ancianos o "principales" que, a través de un riguroso escalafón, han llegado a disfrutar de prestigio y poder. En asuntos internos, este es el núcleo donde, en realidad, reside el poder, pues las autoridades municipales no podrían lograr nada si no cuentan con el apoyo de los "principales".

En lo que se refiere al sistema de parentesco, se puede ob- 
servar, a través de las 32 comunidades que integran la región, diversos grados de transición entre el sistema unilateral de clanes y linajes, propio de la antigua organización Maya, y el de tipo bilateral importado por los españoles.

Intimamente entretejido con la organización familiar, política y religiosa de la comunidad, está el sistema de prácticas y creencias que constituyen el nagualismo; de acuerdo con este sistema, se considera que todo "principal", anciano o simple miembro mayor de clan o de linaje, es dueño de una bestia mítica, de la que puede disponer a voluntad para averiguar lo que ocurre entre los suyos y ejercer castigos de acuerdo con la falta. Como es de suponerse, este es un recurso de control social altamente eficaz. (Para más datos sobre familia y control social, véase Villa Rojas, 1947.)

En el aspecto religioso resulta predominante todo lo relativo al culto católico. El cuidado de la Iglesia y de las ceremonias y rezos que corresponden al santo patronal y a los demás que lo acompañan, es cosa que corresponde a funcionarios diversos, tales como sacristanes, mayordomos y alféreces. Desde luego, la fiesta del santo patrono de la comunidad es la más importante de cuantas se celebran en el curso del año.

Cualquiera que sea la ceremonia religiosa que se practique, es de rigor tener al frente la imagen de la Cruz, ya que se le considera como la representante más inmediata y directa del mismo Dios cristiano que rige el Universo. Junto con él están en el Cielo otros trece santos a los que se menciona como "Los trece piaroles del Cielo", por considerárseles como los fiadores o responsables de los actos humanos ante Dios. Respecto a los motivos que impulsan la vida ceremonial, sobresalen dos: el de que se den bien las cosechas y el de que no falte la salud.

Independientemente de los actos que corresponden al culto católico, existen lugares de adoración en lo alto de los cerros, en las cuevas, fuentes de agua y lagunas, lugares en los que se cree residen otras deidades y seres sobrenaturales que tienen relación con las lluvias, vientos y truenos. En todo esto, se puede ver la supervivencia de antiguas ideas de la tradición indígena.

De modo igual que en todos los otros grupos, la milpa sigue siendo el eje de su estructura económica; a ella dedican la mayor parte de su tiempo y de sus energías. Sus instrumentos de labranza son: el hacha, el machete, el azadón, la coa y, en unos 
pocos lugares, el arado egipcio. La siembra la hacen con el palo endurecido al fuego o con punta metálica al que dan el nombre de avutel (espeque). Cabe advertir que, el citado arado, sólo se usa en los campos de trigo. Aparte del maíz, se siembra frijol, calabaza, chile, chayote, tomate, yuca, camote, papas, cacahuates y legumbres diversas.

La cría de cerdos y el ejercicio de pequeñas artesanías son las fuentes principales de intercambio comercial. En casos de necesidad, existe el recurso de salir como bracero para las fincas de café situadas en la zona de Sacanusco; en esta forma se emplean anualmente unos 15,000 nativos de esta región.

Como nota final sobre estos grupos de Tzeltales y Tzotziles, cabe decir que, en contraste con la falta de estudios sobre los grupos circunvecinos, aquí se cuenta con material abundante, obtenido en fechas recientes por antropólogos de México y de diversas Universidades de Norteamérica; de modo que la bibliografía referente a la región es de lo más extensa y variada.

\section{Los Tojolabales.}

Los Municipios que corresponden a estos indígenas están situados hacia el sur de los Tzeltales, en tierras que colindan con Guatemala. La región, aunque de relieve ondulante, es menos accidentada que la del centro del Estado; la altura de las principales cabeceras fluctúa entre 1,530 m. s. n. m. (La Trinitaria) y 1,596 m. s. n. m. (Comitán). El clima es más bien templado y en ocasiones frío, como para requerir la protección de ponchos o chamarros de lana.

De acuerdo con los datos de 1940 (elaborados por Germán Parra, 1950, págs. 48-9), el número de Tojolabales era de 9,333 individuos, distribuidos en los Municipios de Comitán, La Trinitaria (antes Zapaluta), Independencia y Las Margaritas; de ellos desconocían el español 5,230 que, casi en su totalidad, estaban concentrados en el último de estos Municipios; en los otros tres sólo existían unos 322 , siendo todos los demás bilingües. Ya los que residían en los Municipios de Tzimol y Chicomucelo han quedado incorporados a la lengua nacional. Naturalmente que, a estas alturas (1962) el número de Tojolabales que sólo pueden expresarse en su lengua ha de haber decrecido marcadamente, ya que la población que los rodea 
es mestiza y de habla española. Por otro lado, es de mencionarse que, aunque ya muchos dicen haber olvidado su lengua, siguen usando el traje que los caracterizaba y, también, practicando algunas de sus viejas costumbres.

La indumentaria es bien simple. Los hombres usan calzón y camisa de manta; el calzón les llega hasta las rodillas y la camisa es corta o metida en la pretina del calzón, cuello al estilo chino con alforzas y otros adornos. Algunos llevan cinturón de piel o ceñidor de lana o hilo en color azul, verde o rojo. En días de fiesta llevan pañuelo rojo al cuello. Completan la indumentaria, el sombrero de palma de ala ancha y huaraches de cuero. En tiempo de frío se cubren con un poncho de lana y cuando llueve se cubren con un capote de hojas de palma.

La mujer usa enagua de percal de color azul oscuro y blusa de manga corta; esta blusa no va suelta sino metida en la enagua; está adornada de vistosa manera con alforzas, bordados o listones de color. También la enagua tiene bonitos adornos horizontales tejidos o de cintas. Usan aretes y muchos collares de cuentas de cristal rojo o de otros colores. El pelo se io arreglan de varias maneras, siendo común el partírselo en dos bandas y trenzarlo luego con listón o estambre de color y pasárselo así sobre la cabeza. A manera de rebozo, usan una manta blanca de algodón, llamada toca, que llevan doblada sobre la cabeza. No usan sandalias de ninguna clase. Las muchachas que yo he visto en Comitán y en Zapaluta, son de aspecto agradable y limpio (sobre traje y tipo físico véase De la Cerda Silva, 1957). Es de recordarse que esta es una zona predominantemente mestiza y que, por lo tanto, el traje indígena tiende a desaparecer bajo la presión de la clase dominante.

La habitación es de forma cuadrangular, techo de cuatro aguas, hecho de palma o zacate; lados de bajareque o simples troncos delgados que se unen verticalmente y suelo de tierra apisonada. Existe la tendencia de mejorar estas casas, haciéndolas de teja y adobes (Tejeda Fonseca, 1958, Ms.). En algunos lugares, esta habitación cumple todas las necesidades: cocina, comedor, dormitorio e, inclusive, bodega; en otros, se tiene a corta distancia la choza que sirve de cocina. También es frecuente encontrar el anexo que sirve de temazcal o baño de vapor. Finalmente, dentro del solar están, además, el gallinero y la porqueriza. Estas chozas están distribuidas en calles, 
siendo cada vez más raros los agrupamientos de chozas desperdigadas; se ven, pero más hacia el interior, rumbo a la zona lacandona.

El mobiliario es muy similar al ya descrito para otras zonas indígenas; los muebles de la cocina son los mismos que ya conocemos para hacer tortillas, atoles y frijol; la cama o tapexco es de tables u otates; la hamaca se deja más bien para descansar durante el día, pero no para dormir. Los chamacos duermen en grupos sobre petates. Existen, además, unas cuantas sillas pequeñas, bancas de troncos y una que otra mesa; en el dormitorio, suele verse el pequeño altar doméstico.

La milpa, con los productos que ya conocemos, constituye la base de la economía, auxiliada con la cría de cerdos, aves y algunas artesanías. Entre éstas se cuentan las relativas a cerámica, tejidos y hechura de sombreros y petates. En algunos lugares se ven mulas, burros y caballos para el transporte de los productos a las cabeceras, donde están los centros de comercio.

El sistema de parentesco es bilateral, habiendo ya borrado toda huella de la antigua organización en clanes y linajes. En la actualidad, los trámites matrimoniales se inician entre los propios interesados, es decir, el hombre y la muchacha; ya luego, el novio entrevista a los padres de ella, haciéndoles tres visitas de cortesía en las que les lleva obsequios diversos, tales como chocolate, pan, frutas y ron. Los gastos van por cuenta del novio y la ceremonia final tiene lugar ante las autoridades de la cabecera y, en ocasiones, ante el propio cura. Según Basauri (1940, vol. II, pág. 243) el hombre debe prestar un período de servicio en casa de los suegros, período que suele durar de tres a cuatro semanas, comprendidas desde el día inmediato en que lleva el tercer "bocado" u obsequio, hasta el día de la boda; en todo este tiempo la novia le prepara los alimentos. Ya después, la pareja se instala en su propia choza, construida junto a la de los padres del muchacho.

Tanto en el embarazo como en el parto se siguen costumbres y prácticas que proceden de la tradición aborigen. Desde los primeros meses de embarazo, la mujer recibe la atención de la vecina o parienta que tenga más experiencia en estas cosas; el cuidado principal consiste en masajes con objeto de evitar que el feto quede en posición difícil. La posición al dar a luz es en cuclillas, teniendo la mujer un ceñidor o faja ama- 
rrado arriba de la cintura "para evitar que la criatura suba"; este amarre lo lleva la mujer durante cinco días después del parto para que todo quede en su sitio. Durante el parto, la comadrona pronuncia algunas oraciones católicas en español. La placenta y el cordón umbilical son enterrados sin ceremonia alguna en el piso de la casa (R. Montagu, 1958, Ms.).

Las creencias en la brujería y en el nagualismo están bastante extendidas a través de la región, atribuyéndose a ellas la mayor parte de los casos de enfermedad y muerte.

Los velorios dan lugar a grandes reuniones en los que se obsequia café y un excelente banquete, repartiéndose cigarrillos y aguardiente de rato en rato; en ocasiones dura hasta dos noches (De la Cerda Silva, ibíd., pág. 562). Para el entierro, que tiene lugar en el cementerio del poblado, se emplea una caja negra si se trata de un adulto y blanca si de un niño.

Las autoridades reconocidas por el Gobierno estatal están organizadas de acuerdo con las normas de la estructura municipal. Aparte de ellas están las que corresponden al modo tradicional, en el que ancianos "principales" llevan el control de los asuntos locales. Al tratar de este punto, Basauri (1940, vol. II, págs. 246-7) nos informa a este respecto que:

"En realidad, la verdadera autoridad de los pueblos es la de los principales, pues, éstos ejercen vigilancia sobre todos los aspectos de la vida de la comunidad: moral, administrativo y judicial, e imparten justicia e imponen castigos aún por asuntos domésticos."

En lo que toca a religión, se siguen las enseñanzas de la Iglesia católica. Asisten a la misa dominical, así como a las fiestas de los santos patronales de la región. En algunas casas se hacen rosarios y otros servicios ante el altar de la familia, quedando el ritual a cargo de la rezadora del lugar. Desde luego, Ia fiesta de San Caralampio, que tiene su iglesia en Comitán es la más concurrida y famosa de todas.

Ya para terminar sobre este grupo, queremos indicar que en algunos puntos de su territorio se han instalado pequeños núcleos indígenas de lengua Chuj y Kanhobal procedentes del lado guatemalteco. El caso más interesante es el del poblado de Tziscao, situado a la orilla del lago del mismo nombre y a sólo kilómetro y medio de la línea divisoria con Guatemala. En ese lugar, que tiene 60 casas y unos 427 habitantes, resi- 
den mestizos Tojolabales, Chujes y "Migueleños" de lengua Kanhobal. La migración de estos indígenas de Guatemala se inició desde 1886, en que gentes de San Mateo Ixtatán (de lengua $C h u j$ ) descubrieron la buena calidad de sus tierras. Desde entonces se han agregado muchos más, incluyendo gentes de lenguas Jacalteca y Mam (Tejeda Fonseca, 1958, Ms.). Es en esta región fronteriza de los Tojolabales, donde el maíz produce mazorcas hasta de $70 \mathrm{cms}$. de largo (Blom \& La Farge, vol. II, pág. 429).

\section{Los Mames.}

De acuerdo con la obra "México en Cifras" publicada en 1934 por la Dirección General de Estadística, el número de Mames en aquel tiempo era de 21,685 individuos, de los que 3,420 eran monolingües y el resto bilingües (De la Cerda Silva, 1957, pág. 567). Posteriormente, en los datos de Germán Parra (1950, pág. 49), procedentes del censo de 1940, el número de individuos que ignoraban el español era de 3,372 . Quien esto escribe ignora la cifra actual de Mames monolingües, pero sin duda, ya ha de haberse reducido en forma considerable debido a que la región es preponderantemente mestiza con grandes centros comerciales y de mobilidad social debido al auge de las fincas cafeteras situadas por el rumbo.

La población está repartida en unos 10 Municipios del extremo sur del Estado de Chiapas que colindan o están muy próximos a la frontera con Guatemala (Véase mapa lingüístico en Moisés de la Peña, 1951, Vol. I, pág. 292). Los nombres y población monolingüe de los Municipios son los que siguen:

\section{POBLACION MONOLINGUE MAME}

$\quad$ Municipios
Tapachula
Motozintla
Amatenango de la Frontera
El Porvenir
La Grandeza
El Bejucal
Siltepec
Unión Juárez
Bella Vista
Frontera Comalapa

TOTAL:
Núm. monolingües

1,264

870

501

280

162

116

113

34

28

4. 
La densidad de población en estos Municipios variaba, en 1940, desde 14.04 habitantes por $\mathrm{Km}^{2}$ en Siltepec, hasta 107.28 habitantes por $\mathrm{Km}^{2}$ en La Grandeza. La mayor parte de esa población reside en terrenos altamente quebrados y montañosos donde predominan los climas templado y frío; la altura de sus cabeceras fluctúa desde 168 m. s. n. m. en Tapachula hasta 2,800 m. s. n. m. en El Porvenir.

Lindando con estos Municipios, se encuentran otros habitados por núcleos reducidos de Nahoas, Quichés y Cakchiqueles; los dos últimos proceden de Guatemala. Lo mismo sucede con los Mames, cuyo tronco original está sobre el lado de esta República vecina; los que ahora corresponden a México, quedaron anexados en 1882 al firmarse el Tratado de Límites con esa Nación (Santibáñez, 1911, pág. 17). A partir de esa fecha, se han agregado otros muchos, debido a las erupciones del Tacaná, cuyas cenizas destruían las sementeras y a la atracción de las fincas cafeteras siempre abiertas para el peonaje indígena (Gamio, 1946, pág. 21).

No deja de ser penoso descubrir que, mientras de este lado, carecemos de estudios aceptables sobre tal grupo, del lado guatemalteco contamos con obras excelentes, de las que cabe mencionar la de Wagley (1949) sobre Santiago Chimaltenango; la de Maud Oakes relativa a Todos Santos Cuchumatanes (1951) y, la más reciente, de León Valladares (1957) sobre Colotenango. De manera que para conocer las costumbres originales de estos indios que son de sumo interés, precisa acudir a estas fuentes. Otros puntos que hacen a estos Mames merecedores de estudios cuidadosos, son los de que, según McQuown (1956, pág. 194), es posible que su lengua sea la más conservadora, es decir, la que ha cambiado menos en el curso del tiempo entre las que componen esta familia lingüística. Por otro lado, los estudios botánicos de Mangelsdorf y Cameron (1942) sobre las múltiples variedades de maíz que se cultivan o existen en esa parte de Guatemala habitada por los Mames, les han sugerido la posibilidad de haber sido allí donde tuvieron su origen todas las clases de maíz que ahora se cultivan en México y Norteamérica e, inclusive, haber sido allí donde primero se domesticó esa planta. Susan W. Miles (1960, págs. 430-36) basada en trabajos etnológicos, apoya esta opinión y refiere haber localizado, en 1955, la cueva de Paxil ( situada en el corazón de la zona Mame) en la que, según el 
Popol-Vuh y los Anales de Cakchiqueles, fue descubierta primeramente la existencia del maíz. Aunado a esto, es de recordarse que, el término Mam significa "abuelo" o "ancestro" y que, tanto en Guatemala como Belice, se llama así a las deidades de la montaña que riegan las milpas, tal como hacen los Chaques de Yucatán.

Pasando ahora a la condición cultural que presentan en la actualidad estos Mames del lado mexicano, ya sabemos que, en su mayor parte, han quedado incorporados a las costumbres de la clase campesina nacional, especialmente, en lo que toca a lengua y modo de vestir; respecto a esto último, se dice que las propias autoridades estatales los obligaron a cambiar el traje regional por el de pantalón y camisa que llevan ahora (Gamio, ibíd., pág. 33). De todos modos, el número de los que todavía usan huaraches o van descalzos, es bastante alto. Además, en los lugares alejados, pueden verse hasta hoy hombres que llevan su vieja indumentaria de camisa y calzón de manta, huaraches, sombrero de palma y el ceñidor; lo mismo sucede con la mujer, cuyo traje consistía en un "enredo" de seis metros de largo, de color rojo y adornos blancos, y camisa de mangas cortas y cuello cuadrado. En las regiones frías, los hombres llevan el poncho o chamarro de lana.

La habitación es cuadrada, de cuatro a cinco metros por lado, techos de palma y paredes de bajareque o de simples troncos unidos. En las cabeceras predominan las casas de tejamanil y lados de tablas; como siempre, el piso es de tierra apisonada. Son de una sola pieza que se emplea como cocina, comedor, dormitorio y bodega.

Los utensilios son similares a los que ya conocemos, salvo que, por este rumbo, resulta mayor el número de los artículos comprados en la ciudad, tales como molinos de mano para el nixtamal, objetos de peltre o metálicos, máquinas de coser, lámparas de gasolina o de petróleo, sillas y mesas.

Lo más importante en su economía es el cultivo del maíz, siguiéndole muy de cerca el de la papa. El dinero lo obtienen del trabajo en las fincas de café, el cual ya forma parte integral de su economía.

En lo político se rigen por las normas del gobierno municipal. Y a la influencia de los ancianos y de los "Chimanes" o sacerdotes del culto pagano, está quedando atrás.

La influencia de la Iglesia católica es sobresaliente, aun- 
que sin olvidar por completo algunos aspectos de su vieja religión; a este respecto, se dice que hasta hace una generación se acostumbraba poner la efigie de Tohil a "Dios del Cerro" junto a los santos del altar doméstico. Sobre este punto (Gamio, ibíd., pág. 34) asienta que en algunos lugares de

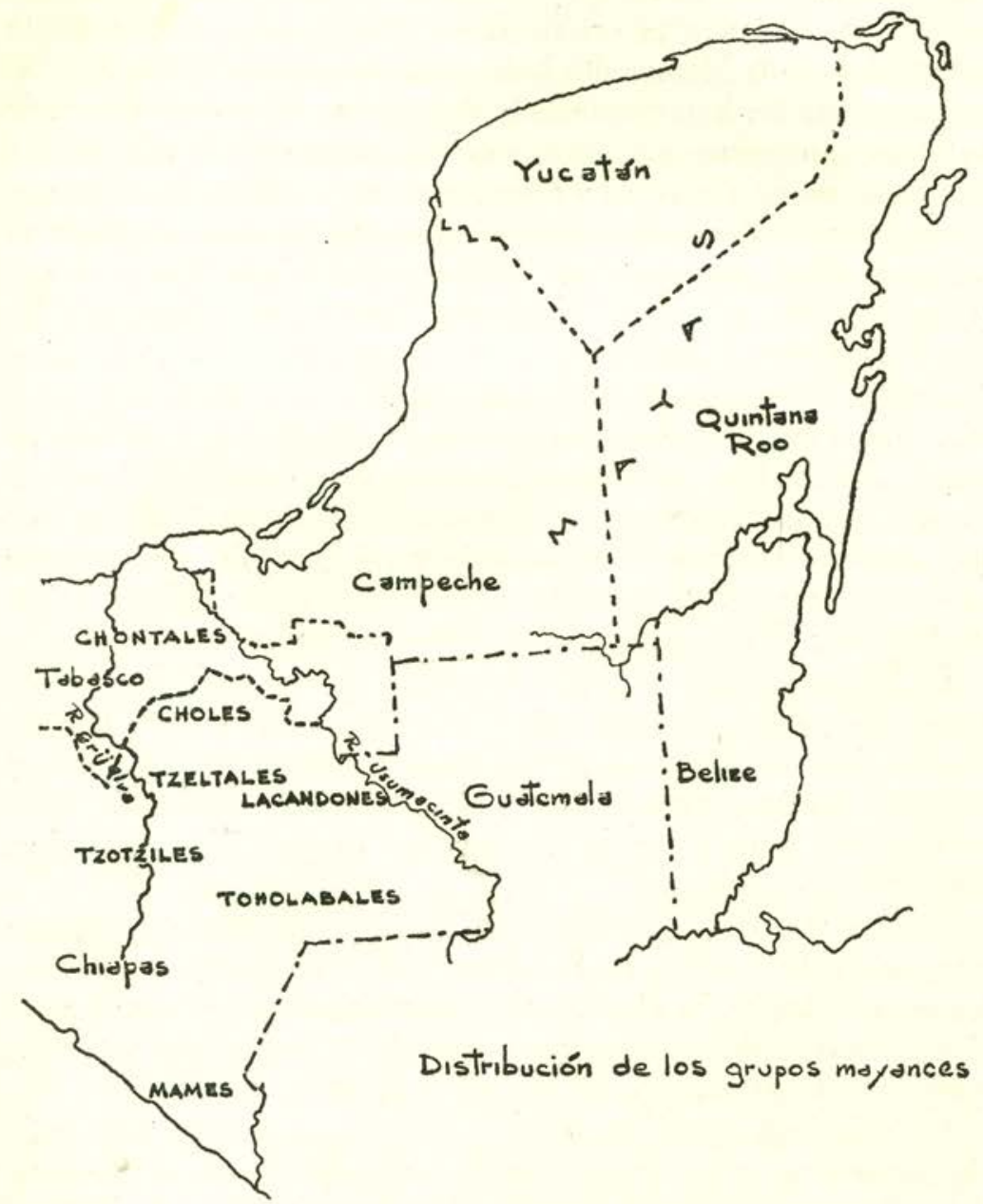

la región, todavía se rinde culto a ídolos prehispánicos que suelen encontrarse en los cerros. El caso concreto mencionado por el doctor Gamio se refiere a un ídolo que, en 1944, se puso en la capilla de la Colonia Agrícola Vicente Guerrero, del Municipio de Angel Albino Corzo; este ídolo es una figura antro- 
pomorfa de $1.80 \mathrm{mts}$. de altura, 55 centímetros de ancho y 30 centímetros de grueso o espesor. Junto a él se ha puesto un letrero que dice: "El Rey del Mundo, Señor del Santuario, 1944." Esto da idea de las supervivencias que todavía han de existir en la región. Independiente de esto, ya han comenzado a ser influciados por misioneros evangelistas de Norteamérica.

Por lo que se refiere al sistema de parentesco ya no queda nada que recuerde la estructura indígena, pues es del tipo bilateral, siguiéndose la terminología usual en español. En lo que sí se puede notar la persistencia de la tradición aborigen es en las prácticas y creencias que tienen relación con las diversas etapas del ciclo de vida.

\section{REFERENCIAS}

Alanís Patiño, Emilio: "La población: problemas demográficos." (Cap. VII, tomo III, de la obra Los recursos naturales del Sureste y su aprovechamiento, 3 vols. Ediciones del Instituto Mexicano de Recursos Naturales Renovables. México, D. F., 1959.)

Amran, David W.: "The Lacandon, last of the Maya." (El México Antiguo. Revista internacional de arqueología, etnografía, folklore, prehistoria, historia antigua y lingüística Mexicanas. Tomo VI, núms. 1-3. México, D. F., 1942.)

Basauri, Carlos: "La población indígena de México." (Tomo II, páginas 125-134. Secretaría de Educación Pública. México, D. F., 1940.)

Blom, Frans \& Duby, Gertrude: La selva lacandona: andanzas arqueológicas. (Editorial Cultura. México, D. F., 1957.)

Blom, Frans \& La Farge, Oliver: "Tribes and Temples." (The Tulane University of Louisiana, New Orleans, La., 1926-1927.)

Charnay, Désiré: "San Cristóbal." (Revista Ateneo. Tuxtla Gutiérrez, Chiapas, México. Traducción parcial de la obra de este autor Le Mexique. Souvenirs et impressions de voyage, publicada originalmente en 1861.) 1956.

De la Cerda Silva, Roberto: "Los Choles." (Contenido en la obra Etnografía de México, págs. 595-506. Instituto de Investigaciones Sociales de la Universidad Nacional Autónoma de México. México, D. F., 1957.

— "Los Tojolabales o Chañabales." (Contenido en la misma obra, págs. 553-564.) 1957.

De la Peña, Morsés T.: Chiapas Económico. (Departamento de Prensa y Turismo. Gobierno del Estado de Chiapas. Tuxtla Gutiérrez. Chiapas, México, 1951.) 
Gamio, Manuel: "Exploración económico-cultural en la región oncocercosa de Chiapas, México." (Sobretiro de América Indigena, volumen VI, núm. 3. Ediciones del Instituto Indigenista Interamericano. México, D. F., 1946.)

Gann, Thomas W. F.: "The Maya Indians of Southern Yucatan and Northern British Honduras." (Smithsonian Institution. Bureau of American Ethnology. Bulletin 64. Washington, D. C., 1918.)

Harris, Margaret: "An introduction to the Chontal of Tabasco, Mex." (América Indigena. Organo trimestral del Instituto Indigenista Interamericano. Vol. VI, núm. 3. México, D. F., 1946.)

León Portilla, Miguel: "Panorama de la población indígena de México." (América Indigena, vol. XIX, núm. 1. México, D. F., 1959.)

McQuown, Norman A.: "The clasification of the Mayan Languages." (Reprinted from International Journal of American Linguistics, vol. 22, No 3, July, 1956.)

Miles, Susan W.: "Mam residence and the maize mith." (Contenido en Culture and History, Essays in honor of Paul Radin, pp. 430-36. Published for Brandeis University by Columbia University Press. New York, 1960.)

Mangeldorf, Paul C. \& Cameron, James W.: "Western Guatemala: A secondary center origin of cultivated maize varieties." (Botanical Museum leaflets, vol. 10, No. 8. Botanical Museum of Harvard University, 1942.)

Montagu, Roberta: "Preliminary summary of a survey in the Tojolabal region, Chiapas, Mexico." (Impresión mimeográfica del "Chiapas Project" de la Universidad de Chicago, 1958.)

OAKES, MAUD: "The two crosses of Todos Santos: survivals of Maya Religion." (Published for Bollingen Foundation Inc. by Panteon Books Inc. New York, N. Y., 1951.)

Parra, Manuel German: "Densidad de la población de habla indígena en la República Mexicana." (Memorias del Instituto Nacional Indigenista, vol. I, núm. 1. México, D. F., 1950.)

Redfield, Robert: "Yucatan: una cultura de transición." (Fondo de Cultura Económica. México, D. F., 1944.)

Redfield, Robert \& Villa Rojas, Alfonso: "Chan-Kom: A Maya village." (The University of Chicago Press. Chicago, Illinois, U. S. A. 1962.)

Russell, James E.: "Some health problems among the Chontals of Tabasco, Mex." (América Indigena. Organo trimestral del Instituto Indigenista Interamericano. Vol. VII, núm. 4. México, D. F., 1947.)

SANTIBÁÑEZ, ENRIQUE: "Chiapas: Reseña geográfica y estadística." (Librería de la Vda. de Ch. Bouret. México, D. F., 1911.)

Scholes, France V. \& Roys, Ralph L.: "The Maya-Chontal Indians of Acalan-Tixchel: a contribution to the history and ethnography of Yucatan Peninsula." (Carnegie Inst. Wash. Pub. 560. Washington, D. C., 1948.)

Soustelle, Georgette: "Observations sur la religion des Lacandons du Mexique Meridional." (Journal de la Société des Américanistes. 
Nouvelle Série. Tome XLVIII, pp. 141-196. Musée de L'Homme. París, 1959.)

Soustelle, JAcQues: "Le totemisme des Lacandons." (Maya Research, 2:325-44. The University of Tulane. New Orleans, La., 1935.)

- "La culture materielle des Indiens Lacandons." (Journal de la Société des Américanistes. Nouvelle Serie. Tome XXIX. Paris, 1937.)

Stephens, John L.: "Incidents of travel in Central America, Chiapas \& Yucatan." (New Brunswick. Rutgers University Press, 1949.)

TeJeda Fonseca, César: "Notas de campo sobre los grupos indígenas de la zona de Tziscao, Chiapas, México." (Impresión mimeográfica del "Chiapas Project" de la Universidad de Chicago. 1958.)

Tozzer, Alfred M.: "A comparative study of the Mayas and the Lacandones." (Published for the Archaeological Institution of America by the Macmillan Company. New York, 1907.)

VALLADAREs, León A.: "El hombre y el maíz: etnografía y etnopsicología de Colotenango." (Guatemala, C. A., 1957.)

Villagutierre Soto-Mayor, Juan de: "Historia de la conquista de la Provincia de el Itzá." (Segunda edición. Biblioteca "Goathemala" de la Sociedad de Geografía e Historia. Vol. IX. Guatemala, C. A., 1933.)

Villa Rojas, Alfonso: "Notas sobre la etnografía de los indios Tzeltales de Oxchuc, Chiapas, México." (Chicago: University of Chicago Library. Microfilm collection of Manuscripts on Middle American Cultural Anthropology, No 7, 1944.)

"The Maya of East-Central Quintana Roo." (Carnegie Inst. of Washington. Pub. 559. Washington, D. C., 1945.)

- "Kinship and nagualism in a Tzeltal community, Southeastern Mexico." (American Anthropologist, vol. 49, № 4. 1947.)

WaGley, Charles: "The social and religious life of a Guatemalan village." American Anthropologist, Memoir Number 71. 1949.)

Ximénez, Fray Francisco: "Historia de la provincia de San Vicente de Chiapa y Guatemala de la Orden de Predicadores." (Biblioteca "Goathemala" de la Sociedad de Geografía e Historia. Volumen 1. Guatemala, C. A., 1929.)

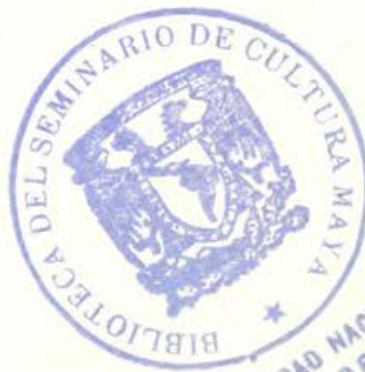

